\title{
WORK-FAMILY CONFLICT AND JOB PERFORMANCE: MODERATING EFFECT OF SOCIAL SUPPORT AMONG EMPLOYEES IN MALAYSIAN SERVICE SECTOR
}

\author{
Nurhafizah Zainal* \\ Universiti Putra Malaysia \\ Dahlia Zawawi \\ Universiti Putra Malaysia \\ Yuhanis Abdul Aziz \\ Universiti Putra Malaysia \\ Mass Hareeza Ali \\ Universiti Putra Malaysia
}

\begin{abstract}
This study aims to examine the relationship between work-family conflict (work interference family and family interference work) and job performance among employees in Malaysian service sector. In addition, this study focuses on exploring the moderating effect of social support received from supervisors and family members on the relationship of work-family conflict dimensions with employee's job performance. This study is employed quantitative method whereby the questionnaires are used to gather the data. The data for the present study were collected from a total of 250 employees working in Malaysian service sector. The mean, standard deviations, correlations, and moderated hierarchical regression analysis were performed in analyzing the data by using the IBM SPSS statistics software 23. The results of the study indicate that work interference family and family interference work are negatively correlated with employee's job performance. Moreover, social support received from supervisors and family members is observed to significantly moderate the relationship of work interference family and family interference work with employee's job performance.
\end{abstract}

Keywords: Work-family conflict; Job performance; Social support; Service sector; Malaysia.

Received: 14 November 2018

Accepted: 30 December 2019

\section{INTRODUCTION}

Work and family are the two important aspects of an individual's life. Most of the people nowadays are carrying the two roles in their life, role as a worker and at the same time role as a family caretaker. Therefore, a great amount of energy and time are required in order to manage fulfillment of these multiple responsibilities. However, balancing multiple roles and

\footnotetext{
* Corresponding Author: Nurhafizah Zainal, Putra Business School, UPM, 43400 Seri Kembangan, Selangor, Malaysia. Email: nurhafizahzainal113@gmail.com
} 
responsibilities may lead to work-family conflict among individuals. For instance, employees who have heavy workloads at the workplace and problems in family are emotionally exhausted. In turn, they are unable to establish a balance between work and family roles (Karatepe, 2013). As according to Greenhause and Beutell (1985), work-family conflict is defined as a form on interrole conflict in which the demands from one domain (work or family) are incompatible with role demands stemming from another domain (family or work). Based on the previous research, workfamily conflict consists of two-dimensional construct where the first dimension indicates the conflict arising when work roles interfere with family roles (work interference family) and second dimension refers to the conflict arising when family-related roles interfere with work roles (family interference work) (Beutell, 2010; Kinnunen, Feldt, Mauno, Rantanen, 2010).

Meanwhile, there are few factors in triggering the work-family conflict situation. The dramatic changes in the composition of families such as a rise of dual-earner, single-parent family and growth in the number of working mothers (Benjamin \& Samson, 2014) has contributed to workfamily conflict. In addition, due to an increase in dual-earner households, non-traditional gender roles, and an increase in the number of hours individual work within each household, conflict between work and family has become part of everyday life for millions of adults (Greenhause, Collins, \& Shaw, 2003). Moreover, in Malaysia, the increase in the number of women in the formal employment sector escalated from 44.5\% in 1982 to 55.3\% in 2018 (Department of Statistics Malaysia, 2018) may be related along the lines of the need to enhance family economy due to high cost of living (Karimi \& Nouri, 2009). Therefore, the changes in society mean that, today more individuals juggle the demands from both work and family than in previous generations of singleearner (Halpern, 2005). The demands from work and family domains can trigger the deleterious impact of work-family conflict.

Previously, research has begun to address the factors that affect work-family conflict (e.g. Mumin \& Syed Khalid Wafa, 2017; Abd Razak, Che Omar, \& Yunus, 2010; Karatepe, Sokmen, Yavas, \& Babakus, 2010) and consequences of work-family conflict (e.g. Benjamin \& Samson, 2014; Burke, Koyuncu, \& Fiksenb, 2013; Karatepe, 2013). However, there is little empirical research conducted to address the consequences of work-family conflict on employee's job performance (e.g. Nohe, Michel, \& Sonntag, 2014; Warokka \& Febrilia, 2014) specifically in Asian context. Therefore, this study is conducted in order to fill in the gap regarding limited research in examining the consequences of work-family conflict towards employee's job performance.

On the other hand, previous research has investigated several moderating factors on work-family conflict such as role salience (Noor, 2010), demographic factors (Benjamin \& Samson, 2014; Yavas, Babakus, \& Karatepe, 2008), and positive affectivity (Karatepe et al., 2010). Yet, there are other potential moderators on work-family conflict that remained largely unexplored. Although inroads have been made in identifying factors that may assist in reducing work-family conflict, there has been a call for additional research to continue to identify mechanisms at the individual level that will lessen the effect of work-family conflict (Frone, 2003). In order to fill in this gap, this study examined how other kinds of individual resources such as social support act as a moderator on the relationship between work-family conflict and employees' job performance. While social support show potential as a way to minimize the negative effect of work-family conflict, the Conservation of Resource Theory provides the theoretical foundation justifying why social support should be considered as a possible moderator in this study. However, the moderating effect of social support towards work-family conflict and job performance has not yet been 
empirically tested specifically in Malaysian service sector. As according to Rathi and Barath (2013), social support received from family and workplace can reduce the negative effect of work and family conflict. In addition, social support from both supervisor and family members may function as protective factors that prevent negative emotions and maladaptive coping strategies when work and family roles collide (Wang, Liu, Zhan, \& Shi, 2010).

The present study has applied Role Theory and Conservation of Resource Theory in explaining the moderating effect of social support on the relationship between work-family conflict and employee's job performance. Role Theory postulated that work-family conflict will result in an undesirable state when individual become difficult to perform many roles successfully (Greenhause \& Beutell, 1985; Kahn, Wolfe, Quinn, Snoek, \& Rosenthal, 1964). In the context of this study, Role Theory is used in examining the effect of work-family conflict on employee's job performance. Meanwhile, Conservation of Resource Theory argued that individual resources may beneficial in protecting them from deleterious impact of work-family conflict (Hobfoll, 1989). In the context of this study, social support is treated as individual resource in weakening the negative impact of work-family conflict on employee's job performance.

\subsection{Research Objectives}

There are four research objectives formulated in this research. The objectives are addressed as follow: (1) to examine the relationship between work interference family and employee's job performance, (2) to examine the relationship between family interference work and employee's job performance, (3) to examine the moderating effect of social support on the relationship between work interference family and employee's job performance, and (4) to examine the moderating effect of social support on the relationship between family interference work and employee's job performance in Malaysian service sector.

\section{LITERATURE REVIEW}

\subsection{The Concept of Work-Family Conflict}

Work and family are the two most recognized domains in one's life given the amount of time spent in these domains, and the variety of experiences, emotions, and challenges experienced when performing specific roles within them (Voydanoff, 2007). The increasing numbers of dual earner parents have led to work-family conflict (Korabik, Lero, \& Whitehead, 2008). Additionally, in recent years, research that associated with work-family conflict has grown tremendously because of the increasing numbers of dual earner parents (Edwards \& Rothbard, 2000; Greenhause \& Parasuraman, 1999; Lambert, 1990; Staines, 1980).

In early 1970 , research on work and family conflict was conceptualized as a one-dimensional construct (Holahan \& Gilbert, 1979). In other words, work-family conflict only be seen as work interference with family. However, Greenhause and Beutell (1985) conceptualized work-family conflict as a two-dimensional construct whereby work roles can interfere with family roles resulting in work interference family and family roles can interfere with work roles resulting in family interference work. The popularity of this conflict perspective stems from the scarcity hypothesis, which assumed that individuals have limited time and energy (Noor, 2010). This is 
consistent with argument proposed by Greenhause and Beutell (1985) that conflict can occur when time devoted to the requirements of one role makes it difficult to fulfil requirements of another role. In addition, strain from participation in one role makes it difficult to fulfil requirements of another role. Moreover, specific behavior required by one role makes it difficult to fulfil requirements of another role. Therefore, occupying multiple roles creates inter-role conflict and role overload which in turn causing negative outcomes.

\subsection{Work-Family Conflict and Job Performance}

Job performance has been defined as discrete behavioral episodes that an individual performs over a standard interval of time (Motowidlo, Borman, \& Schmit, 1997). In a simplest meaning, job performance refers to employees' behaviors at work that support organizational goals. On reviewing and analyzing the existing work on job performance, Welbourne, Johnson and Erez (1998) has taken the initiative to investigate the general factors underlying job performance dimensions since there is a paucity in the literature with regard to the generic factors to measure job performance. They utilized two related theories, namely Role Theory and Identity Theory and suggested five dimensions of job performance namely; job role, career role, innovator role, team role, and organizational role. The current study used job performance construct as proposed by Welbourne et al. (1998) as dependent variable.

Past studies showed that work-family conflict is associated with job performance (Wang \& Tsai, 2014; Odle-Dusseau, Britt, \& Greene-Shortridge, 2012; Choi \& Kim, 2012). The association between work-family conflict and job performance can be explained by using Role Theory and scarcity of resources hypothesis, which proposed that demands of one role deplete personal resources, such as time and physical or mental energy, leaving insufficient resources to allocate to other roles (Edwards \& Rothbard, 2000; Goode, 1960; Marks, 1977). Moreover, employees who have heavy workloads and are unable to establish a balance between work and family roles are emotionally exhausted. Such employees in turn are less embedded in their jobs and display poor job performance in the service delivery process.

\subsection{Moderating Effect of Social Support}

Social support can be considered as a key antecedent in the work-family literature concerning the reduction of work-family conflict (Michel, Mitchelson, Pichler, \& Cullen, 2010). Social support experienced in the work domain should lead to a reduction of the time, attention, and energy needed to perform in work and other roles, thus reducing perceptions and experiences of work-family conflict (Rudolph, Michel, Harari, \& Stout, 2014). Based on the Conservation of Resource Theory argument, social support is considered as condition resource that should be protected in order to minimize the negative impact of stressful situations (Hobfoll, 2002). If such action is not taken, resources will be depleted resulting in a form of burnout (Hobfoll \& Shirom, 1993). In addition, the Conservation of Resource Theory also argued that if individual is successfully protecting his or her resource, then it will be resulting a positive outcome (Hobfoll, 2002).

In addition, Beutell (2010) proposed that social support may help to reduce certain job demands like a difficult or demanding work schedule. For instance, when an employee experiences workfamily conflict, leader support may eliminate the negative appraisal by providing a solution to the problem (Nohe et al., 2014). Similarly, when an employee experiences family interference work, 
support from family and friends may eliminate the negative appraisal by helping the employee to define, understand, and cope with the causes of family interference work (Nohe et al., 2014). Thus, leader and family or friend support is likely to buffer the relationships of work-family conflict (Nohe et al., 2014). Moreover, Kamerman and Kahn (1987) indicated that social support received at the workplace helps in integrating work-family roles, which may reduce inter-role conflict and can lead to better job outcome.

Based on the available literature, Figure 1 shows the proposed research model representing the hypothesized relationships among studied variables.

Figure 1: Proposed Research Model

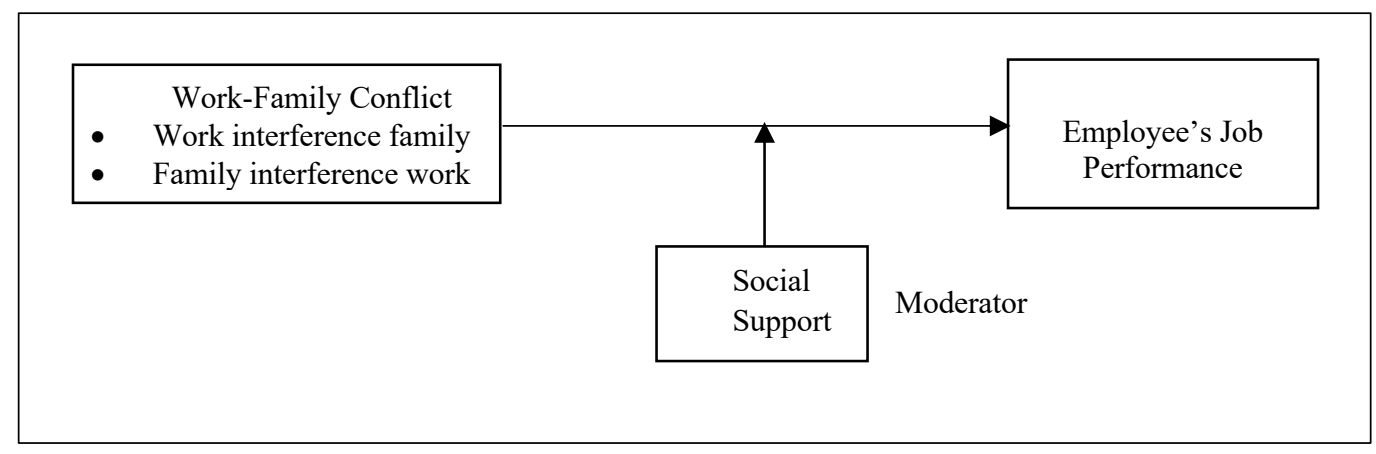

\subsection{Research Hypotheses}

There are four research hypotheses formulated in this study which are:

(1) Work interference family will be negatively correlated with employee's job performance.

(2) Family interference work will be negatively correlated with employee's job performance.

(3) Social support will moderate the relationship between work interference family and employee's job performance. Specifically, social support weakens the negative effect of work interference family on employee's job performance.

(4) Social support will moderate the relationship between family interference work and employee's job performance. Specifically, social support weakens the negative effect of family interference work on employee's job performance.

\section{METHODOLOGY}

\subsection{Population and Sample}

The population for this study referred to lower, middle, and higher levels of employees employed in Malaysian service sector. For the purpose of the current study, the lower level employees are referring to those employees that working at a lower level management such as clerk, secretaries, operative, and supervisory (Robbins \& Coulter, 2012). Meanwhile, middle level employees are referring to those employees that working at middle level management such as executive, departmental head, and managers (Robbins \& Coulter, 2012). In the meantime, higher level 
employees are referring to those employees that working at a higher level management such as vice president, president, and board of directors (Robbins \& Coulter, 2012).

According to the data from Department of Statistics Malaysia, there are 3.6 million of employees working in Malaysia service sector as in the second quarter 2017. However, this study was conducted for employees that working in service companies located in Selangor and Klang Valley area as a sampling. The reason behind this study setting is because of Selangor and Klang Valley are considered as the most developed areas (Gin, 2009) where companies and businesses concentrate their operations (Gross \& Campbell, 2015). Nevertheless, the researcher was unable to get the comprehensive list of employees that working in Selangor and Klang Valley service companies. Therefore, the researcher uses the population data as a reference for a sample size determination later.

Meanwhile, as in the second quarter 2017, there are 1113 service companies in Selangor and Klang Valley registered in MATRADE. Therefore, the sampling frame in this study refers to lower, middle and higher levels of employees that working in 1113 service companies as registered in MATRADE. This group of employees was chosen because most of them are believed in experiencing work-family conflict due to the nature of their work in service companies. Thus, enable the researcher to examine the work-family conflict issues in service companies. Furthermore, these employees are believed to have the ability to accurately answer the questions due to their knowledge and experience.

As identified earlier, the population of this study consists of 3.6 million of employees that working in Malaysia service companies. Therefore, based on the Table provided by Krejcie and Morgan (1970) the sample size needed in this study is at least 384 employees. Since this study employed self-administered questionnaire for data collection, therefore there is a concern about low response rate. Some researchers pointed out that the response rate of surveys is declining in many countries, therefore the issue of non-response and refusal to participate is significance in determining sample size (Bryman \& Bell, 2007). For that reason, the researcher inflated the sample size of 384 by $30 \%$ as many researchers commonly add $30 \%$ to the sample size to compensate for non-response (Cochran, 1963) resulting in a total of 499. However, the researcher has decided to distribute 500 questionnaires due to a rule of thumb from Sekaran (2003), indicated that a sample size larger than 30 and smaller than 500 was appropriate for most study.

There were only 10 service companies had expressed their willingness to participate in this study. The participated service companies consist of different types of service sector such as electricity services (2 companies), oil and gas services (1 company), water supply services (1 company), transportation services ( 2 companies), communication services ( 2 companies), and wholesale services ( 2 companies).

In the context of this study, employees were selected by using purposive sampling technique whereby the researcher specified only employees (lower, middle, and higher level management) that working in Malaysian service sector to be participated in the survey. Specifically, due to the accessibility concern of each participating service companies, the researcher was unable to distribute the questionnaires to the employees. Therefore, the researcher gave full trustworthiness to Human Resource Manager of each participating service companies in distributing the questionnaires. 
The researcher distributed 50 sets of questionnaires to the Human Resource Managers to be distributed to their employees. However, only 268 sets of questionnaires returned and yielding the response rate of $53.6 \%$. A study on the response rate for surveys found that the average response rate for studies that utilized data collected from individuals was 52.7\% (Baruch \& Holtom, 2008). Therefore, the response rate in this study is considered acceptable. However, there were seven questionnaires that had been insufficiently completed as most of the questions were either not answered or the entire questionnaire was blank. These set of questionnaires were omitted from further analysis. Thus, only 261 questionnaires were left, and out of 261 questionnaires, there were 11 cases of outliers identified and hence were removed. In the end, only 250 usable questionnaires were coded and analyzed.

From a total of 250 respondents, 97 respondents (38.8\%) were male. Meanwhile, 153 respondents $(61.2 \%)$ were female. Meanwhile, 92 respondents $(36.8 \%)$ were in the age range of 30 years and below, 86 respondents $(34.4 \%)$ were between 31 and 40 years, and 72 respondents $(28.8 \%)$ were in the range of 41 years or above.

\section{2. $\quad$ Measure}

This study employed quantitative method by distributing questionnaires as a method in data collection. There are four instruments used in order to measure work-family conflict, employee's job performance, and social support. The scales used in this study is based on 4-point Likert scale with response options ranging from 1 for "strongly disagree" to 4 for "strongly agree". The researcher has decided to choose 4-point Likert Scales as all odd-numbered scales have a middle value such as Neutral, and Neither Disagree or Agree. The middle value can be confusing to respondents which may introduce measurement error specifically when a survey question is ambiguous (Losby \& Wetmore, 2012). By using even-numbered scales, the respondents will be more thoughtful and hence eliminates possible misinterpretation of mid-point value (Losby \& Wetmore, 2012). In addition, 4-point Likert Scales is used to eliminate any fence sitter or respondents to select neutral option in answering questionnaire. Moreover, according to Nunnally (1978), increasing the number of Likert Scales would likely not be very meaningful, as the availability of too many possible answers may confuse the respondents and thus raising concerns about validity and reliability. In fact, there are no standard for the number of points in rating scales as common practice varies widely (Krosnick \& Presser, 2010).

The measures used in this study were adopted from previous studies. All measures were translated from English into Bahasa Melayu (national language of the area from where data were collected), and then back-translated into English to ensure equivalency of meaning (Brislin, 1980). The questionnaires were designed in English and were tested prior to distribution by native English speakers to ensure that they were easy to understand. However, due to the nature of the sample population studied, whereby this study involved employees from lower level management who are responsible for routine work might possess lower level of education. Therefore, it was necessary to translate the questionnaires into Malay version. Additionally, before conducting the pilot study, the researcher solicited the opinion from human resource manager in an upscale service companies regarding the preferred language and she opted for the Malay version of the questionnaires. Therefore, the questionnaires were undergone back to back translation before the fieldwork was performed. The translation was performed by a linguistics lecturer at Universiti Kuala Lumpur (UniKL) to resolve any differences due to the difference in language. Additionally, the researcher 
also sought assistance from the Planning and Literature Officer at the Institute of Language and Literature Malaysia or Dewan Bahasa and Pustaka (DBP) to confirm the use of certain words in the questionnaires. Therefore, this study used questionnaires in both languages to suit the needs of the respondents.

Work-family conflict are measured by using Work-Family Conflict Scales developed by Carlson, Kacmar, and Williams (2000). There are 18 items in the instrument to measure work-family conflict. Specifically, there are nine items to measure work interference family and family interference work respectively. In order to measure social support, this study adopted two instruments. First instrument was developed by Tsui, Pearce, Porter, and Tripoli (1997). This instrument was identified as Supervisory Support Scale. This instrument was used to measure social support received from supervisor at the workplace. There are seven items in the Supervisory Support Scale. Meanwhile, the second instrument was Family Support Scale and developed by King, Mattimore, King, and Adams (1995). This instrument was used to measure social support received from family members. There are six items in the Family Support Scale. Meanwhile, employees' job performance was measured by using Role-Based Performance Scale (RBPS) developed by Welbourne et al. (1998). The RBPS contains 20 items.

\subsection{Pre-Test Questionnaire}

In order to ensure the content and face validity of the items, the questionnaires were pre-tested and evaluated by three academicians and two expert panels from the industry. The academicians and expert panels were briefed on the purpose of the study and a relevant explanation was given. They were asked to specify their opinions, comments, and suggestions towards the items in the questionnaires. During the face validity test, some of the opinions and constructive feedback were considered and the content and layout of the questionnaires were refined. For instance, one of the expert panels has suggested to use simplest term in one of the items for measuring work-family conflict. However, the majority of assessors felt that all the questionnaire items should be retained and that the study should proceed to pilot testing.

\subsection{Pilot Study}

The pilot testing of the questionnaires was conducted which using the same category of respondents that would answer the survey during the actual data collection. Pilot testing provided significant feedback on the questions, such as the wording used, employee understanding of the questions, the scales, time taken to answer the questions and quality of the instrument. The pilot testing was conducted in two service companies located in Selangor and Klang Valley area. Prior to the questionnaire distribution, the study obtained permission from the human resources manager of the participating service companies. There were 15 questionnaires distributed to each participating service companies at different time by assistance from human resources manager. Overall, there were 30 questionnaires returned. Hence, the number of respondents is in line with Fink's (1995) suggestion of using at least 10 respondents. The researcher personally monitored the employees and sat down with the employees to observe the completion of the questionnaires to address any problems or clarify ambiguous wordings. Based on the observation, most of the participating employees were able to answer the questions. There were also seem comfortable with the 4-point Likert Scales. Furthermore, there were not confused in choosing an answer and were able to finish 
the questionnaires within the given time. There was no other considerable change derived from the pilot study.

Based on the 30 respondents participated in the pilot study, 13 respondents $(43.3 \%)$ were male. Meanwhile, 17 respondents $(56.7 \%)$ were female. Meanwhile, 10 respondents $(33.3 \%)$ were in the age range of 30 years and below, 14 respondents (46.7\%) were between 31 and 40 years, and six respondents $(20 \%)$ were in the range of 41 years or above. Table 1 presented the Cronbach's alpha values for the reliability analysis of the pilot study. Based on the results, the reliability coefficients show acceptable values of minimum 0.60 (Nunnaly, 1978). Therefore, all the constructs in this study are considered acceptable for further analysis.

Table 1: Cronbach's alpha values for the reliability analysis of the pilot study.

\begin{tabular}{cc}
\hline \hline Constructs & Reliability Coefficients \\
\hline Work Interference Family & 0.82 \\
Family Interference Work & 0.85 \\
Social Support & 0.88 \\
Employee's Job Performance & 0.92 \\
\hline \hline
\end{tabular}

\subsection{Data Analysis}

This study employed IBM SPSS statistics software 23 as a tool in data analysis. Mean and standard deviations are used to examine the level of work-family conflict, social support and employee's job performance in Malaysian service sector. In addition, reliability analysis also has been performed in order to examine the reliability coefficients of the studied variables. Meanwhile, inter-correlations among studied variables are used to examine the relationship among variables. On the other hand, regression analysis was performed to examine the relationship between workfamily conflict and employee's job performance. Moreover, moderated hierarchical regression analysis was used to examine the moderating effect of social support on the relationship between work-family conflict and employee's job performance.

\section{RESULTS}

Table 2 presented the results of the study which consists of means, standard deviations, reliability coefficients, and inter-correlations of the studied variables. Based on the result presented in Table 2 , it can be seen that employees in Malaysian service sector experienced average level of work interference family and family interference work. In addition, it can be seen that employees in Malaysian service sector received average level of social support. Moreover, employees in this study demonstrated average level of job performance. On the other hand, all the construct in this study indicated good reliability based on the reliability coefficients value. Based on the results presented in Table 2, it can be seen that there is a negative significant relationship between work interference family and employee's job performance $(r=-0.18, p<0.01)$. Similarly, results indicated there is a negative significant relationship between family interference work and employee's job performance $(r=-0.22, p<0.01)$. 
Table 2: Results of Means, Standard Deviations, Reliability Coefficients, and Inter-Correlations of The Studied Variables.

\begin{tabular}{lccccccc}
\hline Variables & Mean & SD & $\begin{array}{c}\text { Reliability } \\
\text { Coefficients }\end{array}$ & WIF & FIW & SS & JP \\
\hline WIF & 2.74 & 0.89 & 0.94 & - & & & \\
FIW & 2.72 & 0.89 & 0.95 & 0.80 & - & & \\
SS & 2.69 & 0.62 & 0.85 & -0.17 & -0.28 & - & \\
JP & 2.65 & 0.82 & 0.97 & $-0.18^{* *}$ & $-0.22^{* *}$ & $0.65^{* *}$ & - \\
\hline \hline
\end{tabular}

Notes: SD = standard deviation; WIF = work interference family; FIW = family interference work; SS = social support; JP $=$ employee's job performance. ${ }^{* *} p<0.01$

On the other hand, Table 3 presented the results of regression analysis in order to examine the relationship between work-family conflict and employee's job performance. Based on the Table 3 presented, the value of $R^{2}$ is 0.275 . This means that the model which includes work interference family and family interference work explain $27.5 \%$ of the variance in employee's job performance. In addition, the model in this study reaches statistical significant (Sig. $=0.000$ ). Based on the regression results, the largest beta coefficient is -0.435 which is for family interference work. This means that family interference work makes the strong unique contribution in explaining employee's job performance. Meanwhile, the beta value for work interference family was slightly less (0.264) indicating that it made less of a contribution towards employee's job performance. However, both work interference family and family interference work made a unique and statistically significant $(\mathrm{Sig} .=0.000)$ contribution to the prediction of employee's job performance.

Table 3: Results of Regression Analysis on the Relationship Between Work-Family Conflict and Employee's Job Performance.

\begin{tabular}{clccc}
\hline \hline Model & & $\begin{array}{c}\text { Standardized } \\
\text { Coefficients }\end{array}$ & T & Sig. \\
\hline \multirow{2}{*}{1} & \multicolumn{1}{c}{ Beta } & & \\
\hline & & 0.264 & 18.065 & 0.000 \\
& (Constant) & 2.576 & 0.000 \\
& $\begin{array}{l}\text { Work interference } \\
\text { family }\end{array}$ & -0.435 & -4.241 & 0.000 \\
& $\begin{array}{l}\text { Family } \\
\text { interference work }\end{array}$ & & & \\
\hline \hline
\end{tabular}

$R^{2}=0.275 \quad F=9.946 \quad$ Sig. $=0.000$

Meanwhile, Table 4 presented the results of hierarchical regression analysis in examining the moderating effect of social support towards relationship between work interference family and employee's job performance. In order to test the moderating effect of social support on the relationship between work interference family and employee's job performance, a hierarchical regression model was ran with work interference family in Block 1 and the interaction variable (work interference family $\mathrm{x}$ social support) in Block 2 . Based on the results of the test $\left(\mathrm{R}^{2}\right.$ change $=0.428, \mathrm{~F}$-change $=187.233$, Sig. $\mathrm{F}$ change $=0.000)$ the researchers conclude that social support moderates the relationship between work interference family and employee's job performance. Hence, hypothesis 3 was supported by this finding. 
Table 4: Results of Hierarchical Regression to Test the Moderating Effect of Social Support on The Relationship Between Work Interference Family and Employee's Job Performance.

\begin{tabular}{|c|c|c|c|c|}
\hline & \multicolumn{2}{|c|}{ Model 1} & \multicolumn{2}{|c|}{ Model 2} \\
\hline & $t$-value & $P$-value & $t$-value & $P$-value \\
\hline WIF & -1.337 & 0.182 & -11.702 & 0.000 \\
\hline WIF*SS & & & 13.683 & 0.000 \\
\hline $\mathrm{R}^{2}$ change & \multicolumn{2}{|c|}{0.007} & \multicolumn{2}{|c|}{0.428} \\
\hline F-change & \multicolumn{2}{|c|}{1.788} & \multicolumn{2}{|c|}{187.233} \\
\hline Sig. F change & \multicolumn{2}{|c|}{0.182} & \multicolumn{2}{|c|}{0.000} \\
\hline
\end{tabular}

Notes: WIF $=$ work interference family, $\mathrm{SS}=$ social support.

In addition, Table 5 presented the results of hierarchical regression to test the moderating effect of social support on the relationship between family interference work and employee's job performance. The researchers ran a hierarchical regression model with family interference work in Block 1 and the interaction variable (family interference work x social support) in Block 2. Based on the results of the test $\left(\mathrm{R}^{2}\right.$ change $=0.401, \mathrm{~F}$-change $=179.972$, Sig. F change $\left.=0.000\right)$ the researchers conclude that social support moderates the relationship between family interference work and employee's job performance. Hence, hypothesis 4 was supported by this finding.

Table 5: Results of Hierarchical Regression To Test The Moderating Effect of Social Support

On The Relationship Between Family Interference Work and Employee's Job Performance.

\begin{tabular}{|c|c|c|c|c|}
\hline & \multicolumn{2}{|c|}{ Model 1} & \multicolumn{2}{|c|}{ Model 2} \\
\hline & $t$-value & $P$-value & $t$-value & $P$-value \\
\hline FIW & -3.600 & 0.000 & -13.233 & 0.000 \\
\hline FIW*SS & & & 13.415 & 0.000 \\
\hline $\mathrm{R}^{2}$ change & \multicolumn{2}{|c|}{0.050} & \multicolumn{2}{|c|}{0.401} \\
\hline F-change & \multicolumn{2}{|c|}{12.959} & \multicolumn{2}{|c|}{179.972} \\
\hline Sig. F change & \multicolumn{2}{|c|}{0.000} & \multicolumn{2}{|c|}{0.000} \\
\hline
\end{tabular}

Notes: FIW = family interference work, $\mathrm{SS}=$ social support.

\section{DISCUSSION}

This study aims to examine the effect of work-family conflict on employee's job performance in Malaysian service sector. Moreover, this study aims to examine the moderating effect of social support on the relationship between work-family conflict and employee's job performance. The results of the study served theoretical implication towards Role Theory used in this study. Specifically, the findings of this study indicate that employee's job performance will be decrease if employees experienced high work interference family and family interference work. This finding was consistent with previous study from Majekodunmi (2017) reported that work interference family had a strong negative relationship on employee's job performance. Employees who experienced high work interference family are feel exhausted with limited time and energy that they have and thus unable to concentrate on their job. This is consistent with argument from Karatepe (2013), employees who have heavy workloads are unable to establish a balance between work and family roles and are emotionally exhausted and in turn are less embedded in their jobs 
and display poor job performance. In addition, with regard to the relationship between family interference work and employee's job performance, the finding of this study was consistent with previous research (Lee, Veasna, \& Wu, 2013; Nohe et al., 2014). Furthermore, Nohe et al. (2014) indicated that family demands can interfere with work responsibilities and generate negative consequences for employees. The negative significant relationship of work interference family and family interference work toward employee's job performance were consistent with Role Theory assumptions. Role Theory posited that individual will experience negative consequences in stressful situation such as in work-family conflict (Kahn et al., 1964). Therefore, the findings in this added theoretical implication on the applicability of Role Theory in viewing negative consequences of work-family conflict among employees in Malaysian service sector. Based on the above-mentioned findings, it is advisable for service organizations in considering seriously about the work-family conflict among their employees as work-family conflict can cause deleterious impact on employee's job performance.

Along the same line, the results also provide theoretical implication on the applicability of Conservation of Resource Theory used in this study. The findings indicate that social support significantly moderated the relationship between work-family conflict (work interference family and family interference work) and employee's job performance. This finding is consistent with empirical study from Lee, Lin, Chen and Huang (2017) who found that social support is significantly related with employee's job performance. In addition, the finding of this study is consistent with argument from Wang et al. (2010) argued that social support received from family and supervisor may function as protective factors that prevent negative emotions and maladaptive coping strategies when work and family roles collide. Thus, employees that received social support may increase their job performance. Moreover, according to Das, Kumari and Pradhan (2015), when an employee experiences family interference work, support from family members may help employees in increasing their job performance. On the other hand, Pluut, Llies, Curseu, and Liu (2018) reported that when employees received social support from supervisor, it will minimize the deleterious impact of work interference family and thus increasing their job performance. Therefore, it can be seen that the findings of this study added theoretical implication on the applicability of Conservation of Resource Theory in resources (social support) used to minimize the negative impact of work-family conflict. Thus, service organizations could boost up the employee's job performance by providing adequate social support at the workplace such as supportive supervisors, flextime, and friendly family policies. On the other hand, family members should play important role in providing assistance to employees in lessening the burden of household duties by helping out each other.

\subsection{Limitations of the Study and Directions for Future Research}

Each research project that is conducted in any field of study is always vulnerable to certain limitations that might affect the study. This limitation is due to the fact that it is almost impossible to conduct a study that covers all dimensions. With regard to the current study, there are few limitations have been identified. Based on the limitations, more additional studies can be carried out to further investigate the area and scope of the study so that better research can be conducted in the future.

First, the study has focused on service organizations and treats social support as moderating variables to examine its impact on work-family conflict and employee's job performance. The 
study did not test other constructs as moderating variables. Thus, creating limitation in this study. It is suggested that future study should look into the possibility of other variables such as personality traits as moderator in examining the impact of work-family conflict on employee's job performance. Personality traits are expected to play some important roles in influencing workfamily conflict (Nurhazirah, Nor Irvoni, Wan Edura, \& Mohd Saidfudin, 2012) and thus impacting employee's job performance. In addition, it is suggested that future studies should expand the proposed research model in this study by integrate other related theories in order to understand the negative impact of work-family conflict.

Second, in terms of research design, the study employed only quantitative methods, whereas employing a mixed method might have a greater impact on the results of the study. Therefore, future research should consider using both methods to gain more vigorous findings. For example, future study could conduct an interview session with supervisors in order to examine the employee's job performance. Specifically, it is recommended for future studies to collect data at two different points of time in order to measure employee's job performance. This is because employee's job performance is changes from time to time (Ryff, 1995 \& Motowidlo et al., 1997).

Third, it should be noted that the data and findings that were reported were derived from exploratory research in a single country and service industry setting. This limitation raises questions about the generalizability of this study to different cultures and different industry. As such, the results are applicable to the Malaysian service organizations and it may also provide insights into service organizations in other countries with similar culture perspective. Further research is needed particularly with regard to other countries, as this expansion may help to improve the understanding of the work-family conflict. Specifically, future research could examine work-family conflict in other countries with different cultures such as country from Asian and Western cultures. The differences in cultures could provide different insight on viewing the impact of work-family conflict due to different perceptions (Warokka \& Febrilia, 2014). Therefore, the comparisons could be made in assessing work-family conflict and added to the body of knowledge.

Fourth, for sample limitation, the study involved different types of service organizations such as electricity services, transportation services, communication services and many more based on the organizations' willingness to participate in this study. However, this study failed to obtain equal number of different types of service organizations. Different types of services would have different nature of works. Therefore, the findings of this study might be affected by this situation. It is very beneficial if future study could be obtained equal number of all different types of service organizations. In a similar vein, this study only conducted in service organizations located in Selangor and Klang Valley. This area is considered as the most developed areas where companies and business concentrate their operations. Due to time constrains, the data cannot be collected from service organizations in the whole Malaysia. Thus, creating limitations in this study since there are many more service organizations that operated outside Selangor and Klang valley area.

\section{CONCLUSION}

This study is deemed important as it has several implications for employees as well as for organizations especially for the service companies. On the employees' side, they should know on 
how to reduce their work-family conflict in order to lessen the negative consequences of workfamily conflict. In addition, service companies should aware about the deleterious impact of workfamily conflict has on employees. Moreover, service companies should concern about workfamily conflict experienced by their employees and how to give appropriate support for those employees. The results of the study indicate that work interference family and family interference work are negatively related with employee's job performance. Meanwhile, results also indicate that social support is able to weaken the negative relationship between work-family conflict (work interference family and family interference work) and employee's job performance. This study contributes to the body of knowledge in work-family conflict literatures. As a conclusion, workfamily conflict is an important issue among employees as it may has detrimental consequences. However, necessary action can be taken in order to eliminate the negative consequences of workfamily conflict among employees.

\section{ACKNOWLEDGEMENT}

The researchers would like to thank employees in Malaysian service sector for their willingness to participate in a survey conducted in this study.

\section{REFERENCES}

Abd Razak, A. Z. A., Che Omar, C. M. Z., \& Yunus, J. N. (2010). Family issues and work-family conflict among medical officers in Malaysian public hospitals. International Journal of Business and Social Science, 1(1), 26-35.

Baruch, Y., \& Holtom, B. C. (2008). Survey response rate levels and trends in organizational research. Human Relations, 61(8), 1139-1160.

Benjamin, O. A., \& Samson, B. S. (2014). The impact of demographic factors on family interference with work and work interference with family and life satisfaction. International Journal of Humanities and Social Science Invention, 3(4), 31-38.

Beutell, N. J. (2010). Work schedule, work schedule control and satisfaction in relation to workfamily conflict, work-family synergy, and domain satisfaction. Career Development International, 5(5), 501-518.

Brislin, R. W. (1980). Translation and content analysis of oral and written material. In H. C. \& Berry, J. W. (Eds). Handbook of Cross-cultural Psychology, 2. Allyn and Bacon: Boston, 389-444.

Bryman, A., \& Bell, E. (2007). Business research method. New York: Oxford.

Burke, R. J., Koyuncu, M., \& Fiksenb, L. (2013). Antecedents and consequences of work-family conflict and family-work conflict among frontline employees in Turkish hotels. Journal of Management Research, 5(4), 39-56.

Carlson, D. S., Kacmar, K. M., \& Williams, L. J. (2000). Construction and validation of a multidimensional measure of work-family conflict. Journal of Vocational Behavior, $56(2), 249-276$.

Choi, H. J., \& Kim, Y. T. (2012). Work-family conflict, work-family facilitation, and job outcomes in the Korean hotel industry. International Journal of Contemporary Hospitality Management, 24(7), 1011 - 1028.

Cochran, W. G. (1963). Sampling techniques. New York: John Wiley and Sons, Inc. 
Das, S., Kumari, S., \& Pradhan, R. (2015). Relationship of family support with job satisfaction and job performance of staff nurses. International Journal of Advances in Nursing Management, 3(2), 1-8.

Department of Statistics, Malaysia. (2018). Survey report statistics. Retrieved from https://www.dosm.gov.my

Edwards, J. R., \& Rothbard, N. P. (2000). Mechanisms linking work and family: Clarifying the relationship between work and family constructs. Academy of Management Review, 25(1), 178-199. doi:10.5465/AMR.2000.2791609.

Fink, A. (1995). How to sample in surveys. California: SAGE Publications Inc.

Frone, M. R. (2003). Work-Family Balance. In J. Campbell Quick \& L. E. Tetrick (Eds.), Handbook of occupational health psychology (pp. 143-162). Washigton DC: American Psychological Association.

Gin, O. K. (2009). Historical dictionary of Malaysia. USA: The Scarecrow Press.

Goode, W. J. (1960). A theory of role strain. American Sociological Review, 25(4), 483-496. doi: $10.2307 / 2092933$.

Greenhause, J. H., \& Beutell, N. J. (1985). Sources of conflict between work and family roles. Academy of Management Review, 100(1), 76-88.

Greenhause, J. H., Collins, K. M., \& Shaw, J. D. (2003). The relation between work-family balance and quality of life. Journal of Vocational Behavior, 63(3), 510-531.

Greenhause, J. H., \& Parasuraman, S. (1999). Research on work, family, and gender: current status and future directions. In G. N. Powell (Ed.), Handbook of gender and work (pp. 391-412). Thousand Oaks, CA: Sage Publications.

Gross, S., \& Campbell, N. (2015). Central city vibrancy and new business venturing. Journal of Entrepreneurship and Public Policy, 4(2), 257-271.

Halpern, D. F. (2005). Psychology at the intersection of work and family: Recommendations for employers, working families, and policymakers. American Psychologist, 60, 397-409.

Hobfoll, S. E. (1989). Conservation of resources: A new attempt at conceptualizing stress. Psychology, 6, 307-324.

Hobfoll, S. E. (2002). Social and psychological resources and adaptation. Review of General Psychology, 6, 307-324.

Hobfoll, S. E., \& Shirom, A. (1993). Stress and Burnout in the Workplace: Conservation of Resources. In R. T. Golembiewski (Ed.), Handbook of organizational behavior (pp. 4161). New York: Dekker.

Holahan, C. K., \& Gilbert, L. A. (1979). Inter-role conflict for working women: Careers versus jobs. Journal of Applied Psychology, 64, 86-90.

Kahn, R. L., Wolfe, D. M., Quinn, R. P., Snoek, J. D., \& Rosenthal, R. A. (1964). Organizational stress: Studies in role conflict and ambiguity. Oxford, England: John Wiley.

Kamerman, S. B., \& Kahn, A. J. (1987). The responsive workplace: Employers and a changing labor force. New York: Columbia University Press.

Karatepe, O. M. (2013). The effects of work overload and work-family conflict on job embeddedness and job performance: The mediation of emotional exhaustion. International Journal of Contemporary Hospitality Management, 25(4), 614-634. doi:10.1108/09596111311322952.

Karatepe, O. M., Sokmen, A., Yavas, U., \& Babakus, E. (2010). Work-family conflict and burnout in frontline service jobs: Direct, mediating and moderating effects. Ekonomika A Management, 4, 61-73. 
Karimi, L., \& Nouri, A. (2009). Do work demands and resources predict work-to-family conflict and facilitation? A study of Iranian male employees. Journal of Family and Economic Issues, 30(2), 193-202.

King, L. A., Mattimore, L. K., King, D. W., \& Adams, G. A. (1995). Family support inventory for workers: A new measure of perceived social support from family members. Journal of Organizational Behavior, 16, 235-258.

Kinnunen, U., Feldt, T., Mauno, S., \& Rantanen, J. (2010). Interface between work and family: A longitudinal individual and crossover perspective. Journal of Occupational and Organizational Psychology, 83(1), 119-137.

Korabik, K., Lero, D. S., \& Whitehead, D. L. (2008). Work-family integration: introduction and overview. In K. Korabik, D. S. Lero, \& D. L. Whitehead (Eds.), Handbook of work-family integration: Research, theory and best practices (pp. 3-11). London: Academic Press.

Krejcie, R. V., \& Morgan, D. W. (1970). Determining sample size for research activities. Educational and Psychological Measurement, 30, 607-610.

Krosnick, J. A., \& Presser, S. (2010). Handbook of survey research. Emerald Group Publishing.

Lambert, S. J. (1990). Processes linking work and family: A critical review and research agenda. Human Relations, 43, 239-257.

Lee, L., Veasna, S., \& Wu, W. (2013). The effects of social support and transformational leadership on expatriate adjustment and performance. Career Development International, 18(4), 377-415. doi:10.1108/CDI-06-2012-0062.

Lee, Y. D., Lin, C. C., Chen, M. T., \& Huang, C. F. (2017). The impact of social support on job performance: The empirical study of mediating and moderating effects of related variables. International Journal of Organizational Innovation, 10(1), 290-317.

Losby, J., \& Wetmore, A. (2012). Using Likert scales in evaluation survey work. Retrieved from https://www.cdc.gov/dhdsp/pubs/docs/cb.

Majekodunmi, A. E. (2017). Work-family conflict and family-work conflict as correlates of job performance among working mothers: Implications for industrial social workers. African Journal of Social Work, 7(1), 52-62.

Marks, S. R. (1977). Multiple roles and role strain: Some notes on human energy, time and commitment. American Sociological Review, 42, 921-936.

Michel, J. S., Mitchelson, J. K., Pichler, S., \& Cullen, K. L. (2010). Clarifying relationships among work and family social support, stressors, and work-family conflict. Journal of Vocational Behavior, 76, 91 - 106.

Motowidlo, S. J., Borman, W. C., \& Schmit, M. J. (1997). A theory of individual differences in task and contextual performance. Human Performance, 10(2), 71-83.

Mumin, N., \& Syed Khalid Wafa, S. A. W. (2017). Personality and work-family conflict from the perspective of service industry in Malaysia. Malaysian Journal of Business and Economics, 4(1), 15-30.

Nohe, C., Michel, A., \& Sonntag, K. (2014). Work-family conflict, social support, and turnover intentions: A longitudinal study. Journal of Vocational Behavior, 85, 1-12.

Noor, N. M. (2010). Work-family conflict, work and family-role salience, and women's wellbeing. The Journal of Social Psychology, 144(4), 389-405. doi:10.3200/SOCP.144.4.389-406.

Nunnally, J. C. (1978). Psychometric theory. New York: McGraw-Hill.

Nurhazirah, H., Nor Irvoni, M. I., Wan Edura, W. R., \& Mohd Saifudin, M. (2012). Personality traits, work-family conflict and job satisfaction: Items validity using Rasch measurement approach. Social and Behavioral Sciences, 65, 1013-1019. 
Odle-Dusseau, H. N., Britt, T. W., \& Greene-Shortridge, T. M. (2012). Organizational workfamily resources as predictors of job performance and attitudes: The process of workfamily conflict and enrichment. Journal of Occupational Health Psychology, 17(1), 2840. doi:10.1037/a0026428.

Pluut, H., Ilies, R., Curseu, P. L., \& Liu, Y. (2018). Social support at work and at home: Dualbuffering effects in the work-family conflict process. Organizational Behavior and Human Decision Processes, 146, 1-13.

Rathi, N., \& Barath, M. (2013). Work-family conflict and job and family satisfaction: Moderating effect of social support among police personnel. Equality, Diversity and Inclusion: An International Journal, 32(4), 438-454. doi:10.1108/EDI-10-2012-0092.

Robbins, S. P., \& Coulter, M. (2012). Management. Prentice Hall: Pearson.

Rudolph, C., S. Michel, J., B. Harari, M., \& J. Stout, T. (2014). Perceived social support and workfamily conflict. Cross Cultural Management: An International Journal, 21(3), 306-325. doi:10.1108/CCM-01-2013-0002.

Ryff, C. D. (1995). Psychological well-being in adult life. Current Directions in Psychological Science, 4(4), 99-104.

Sekaran, U. (2003). Research methods for business. New Jersey: John Wiley.

Staines, G. L. (1980). Spillover versus compensation: A review of the literature on the relationship between work and non-work. Human Relations, 33, 111-129.

Tsui, A. S., Pearce, J. L., Porter, L. W., \& Tripoli, A. M. (1997). Alternative approaches to the employee-organization relationship: Does investment in employee pay off? Academy of Management Journal, 40(5), 1089-1121.

Voydanoff, P. (2007). Work, family, and community: Exploring interconnections. Mahwah, NJ: Routledge Publishing.

Wang, M. L., \& Tsai, L. J. (2014). Work-family conflict and job performance in nurses: The moderating effects of social support. The Journal of Nursing Research, 22(3), 200-207. doi:10.1097/jnr.0000000000000040.

Wang, M., Liu, S., Zhan, Y., \& Shi, J. (2010). Daily work-family conflict and alcohol use: Testing the cross-level moderation effects of peer drinking norms and social support. Journal Applied Psychology, 95(2), 377-386.

Warokka, A., \& Febrilia, I. (2014). Work-family conflict and job performance: Lesson from a Southeast Asian emerging market, 2015(2015), 1-15.

Welbourne, T. M., Johnson, D. E., \& Erez, A. (1998). The role-based performance scale: Validity analysis of a theory-based measure. Academy of Management Journal, 41(5), 540-555.

Yavas, U., Babakus, E., \& Karatepe, O. M. (2008). Attitudinal and behavioral consequences of work-family conflict and family-work conflict: Does gender matter? International Journal of Service Industry Management, 19(1), 7-31. 